\title{
Corpus
}

Archivos virtuales de la alteridad americana

Vol 1, No 2 | 2011

Julio / Diciembre 2011

\section{Arqueología y ¿genocidio cultural?}

\section{Verónica Seldes}

\section{OpenEdition}

\section{Journals}

Electronic version

URL: http://journals.openedition.org/corpusarchivos/1162

DOI: $10.4000 /$ corpusarchivos. 1162

ISSN: 1853-8037

\section{Publisher}

Diego Escolar

\section{Electronic reference}

Verónica Seldes, «Arqueología y ¿genocidio cultural? », Corpus [En línea], Vol 1, No 2 | 2011, Publicado el 30 diciembre 2011, consultado el 30 abril 2019. URL : http://journals.openedition.org/ corpusarchivos/1162; DOI : 10.4000/corpusarchivos.1162

This text was automatically generated on 30 April 2019.

Licencia Creative Commons: Atribución-NoComercial 2.5 Argentina (CC BY-NC 2.5 AR) 


\title{
Arqueología y ¿genocidio cultural?
}

\author{
Verónica Seldes
}

1 El Estado Nación Argentino se conformó a partir de la construcción de un modelo de unidad territorial, acompañado de un proceso civilizatorio con fuertes componentes de racismo, la institucionalización de un estado monoétnico y una supuesta "homogeneidad cultural" en su interior (Bechis 1992). En este proceso, el estado se constituyó invisibilizando al "otro interno" desde una praxis y un discurso naturalizador y legitimador de un proyecto de país que subsumió su diversidad cultural bajo el discurso del "ser argentino" (Delrio et al 2010).

2 Considerando que la ciencia construye discursos hegemónicos que responden a sus contextos sociopolíticos de producción, y que esto tiene consecuencias tanto sociales como políticas (Endere y Curtoni 2006), en este trabajo nos centraremos en los discursos que produjo la arqueología en sus inicios y en cuánto contribuyó con esto a legitimar y naturalizar una historia que podríamos denominar de "genocidio cultural". ${ }^{1}$

3 En este sentido, resulta interesante el ejercicio de deconstruir los discursos hegemónicos de la ciencia realizando una genealogía de su papel en la legitimación de un determinado proyecto de estado, a la vez que una reflexión sobre la práctica arqueológica tanto en el pasado como en la actualidad.

\section{Siglo XX, ¿cambalache?}

4 El objetivo de la arqueología de principios del siglo pasado consistía en la identificación y clasificación de los pueblos prehispánicos que habitaron el territorio argentino. La arqueología de esta época clasificó a las culturas prehispánicas otorgándoles límites territoriales precisos. Estas supuestas fronteras culturales y territoriales no tenían asidero en lo que los restos arqueológicos evidenciaban, tratándose de fronteras "inventadas"; sin embargo, se sostuvieron por mucho tiempo en las publicaciones científicas (Delfino y Rodriguez 1991, Zaburlin 2009). 
Casualmente estas fronteras arqueológicas coincidían con las fronteras políticas de nuestro país (al menos en el Noroeste Argentino). Esto implicaba unos límites para nuestro estado - nación casi inmemoriales, naturalizan-do una frontera política que lejos estaba de representar una frontera histórica y mucho menos cultural (Zaburlin 2009).

De esta manera la ciencia, que no estuvo desvinculada a lo largo de su historia de su contexto de producción, de alguna manera avaló con su práctica un proyecto político de época que necesitaba establecer límites territoriales precisos para su reciente estado nación (Trinchero 2000).

\section{Ecos del silencio}

Bien viene traer a colación la "exótica" construcción de una pirámide en la cima del Pucará de Tilcara (Quebrada de Humahuaca, Jujuy), monumento "emblemático" erigido en 1935. Emblemático de qué? Probablemente de la forma de pensar la arqueología de esa época (Belli et al 2005).

8 Hay varias cuestiones interesantes para resaltar respecto a la famosa "pirámide del pucará", punto casi obligado para el turismo. Una de ellas es que esta forma constructiva no representa ningún aspecto de la arquitectura local; por otra parte, se diseñó destruyendo las construcciones originales y colocando un monumento "importado" sobre lo que fue uno de los lugares centrales del asentamiento (Zaburlin 2009). Sobre todo, habiendo demolido las construcciones originales, se construyó en homenaje a los arqueólogos que allí trabajaron, poniendo en perspectiva central a los arqueólogos e invisibilizando de esta manera la arquitectura prehispánica. Pero aún más interesante resulta la placa colocada en el frente de la pirámide cuya leyenda dice: "De entre las cenizas milenarias de un pueblo muerto exhumaron las culturas aborígenes dando eco al silencio".

9 Luego de tomarnos un momento otorgando un espacio a ese "eco del silencio", aquí nos interesa reflexionar si con este tipo de práctica profesional no se ha colaborado a ese proceso que hemos denominado "genocidio cultural", mediante la negación, en este caso, del vínculo histórico entre los antiguos habitantes y los actuales: unas prácticas culturales "muertas", "perdidas"; un pasado lejano del cual, para los arqueólogos de la época, no quedaban más que sus restos materiales.

\section{Doble juego}

10 En este punto podemos retomar las reflexiones de Zaburlin (2009), quien refiere a la relación entre este tipo de práctica arqueológica y el proyecto político del período. De acuerdo a la autora, es posible hablar de un doble juego perverso en el cual la arqueología promovía una historia ficticia acerca de los límites del territorio del norte argentino (por su identificación una cultura = un territorio) que justificaban por lo tanto esos límites nacionales $\mathrm{y}$, por otro lado, les negaba la historicidad a los pueblos originarios contemporáneos porque lo que los "científicos" estudiaban, eran "culturas muertas".

11 Son estos algunos ejemplos que hemos elegido para dar cuenta de qué manera la ciencia, en este caso el discurso arqueológico, contribuyó de alguna manera a in-visibilizar la historia de las poblaciones locales quitándoles su historia, porque a un "pueblo muerto" no se le busca la continuidad. 

propuestas de desarrollo económico provenientes de sectores hegemónicos (Belli et al 2005), implica, es cierto, una revalorización de su historia. Lo que antes era invisibilizado ahora aparece con un status especial, ahora tiene valor. "Hay que ponerlo en valor", se escucha recurrentemente, incluyendo propuestas arqueológicas de "puesta en valor del patrimonio". invisibilizado como parte de un proceso legitimador del Estado - nación, hoy es recuperado y resignificado.

Por un lado, proponemos reflexionar sobre lo que significa implementar un proyecto patrimonializador desligado de las propias representaciones de la población (Belli et al 2005). A su vez sería interesante discutir sobre las consecuencias sociales de la práctica arqueológica: ser conscientes de la necesidad de que la ciencia no vuelva a repetir discursos "legitimadores" de prácticas hegemónicas. La permanente autocrítica de las 
ciencias sociales se impone como estrategia de evaluación de las implicancias de utilizar conceptos como "patrimonio" o "puesta en valor", desnaturalizando y deconstruyendo los propios discursos para que no se conviertan en nuevas herramientas legitimadoras (Boasso 2005). En definitiva el desafío es trabajar por una ciencia que no esencialice ni naturalice lo que es resultado de determinados procesos políticos (Trinchero 2000). La "construcción de la argentinidad" es un ejemplo. La "patrimonialización de una región" ¿podría ser otro?

21 Frente al reciente redescubrimiento de la arqueología por parte de la comunidad en general y del lugar que ahora se le otorga para acompañar el proceso de patrimonialización de la región, el arqueólogo debería posicionarse desde un lugar crítico frente a los discursos triunfalistas acerca de los "beneficios" que este proceso tiene para la población local. Beneficios que no vaya a ser que impliquen una nueva forma de encubrimiento de la diversidad cultural.

\section{Veinte años no es nada}

En los últimos veinte años la arqueología ha comenzado a cuestionar esa forma "tradicional" de ejercer su práctica, alejada del contexto y de la realidad en la que trabaja, promoviendo lo que antes era arqueología para especialistas y destinada a engrosar las vitrinas de los museos. En este sentido distintos grupos de investigación han llevado adelante proyectos vinculados a generar aportes en el esclarecimiento y difusión de procesos genocidas recientes, más exactamente durante la última dictadura militar (1976 - 1983). Los trabajos en el "Club Atlético", "Pozo de Rosario", "El Vesubio" y "Mansión Seré" son algunos de los ejemplos que incluyeron en algunos casos la participación de arqueólogos como peritos y testigos de causas judiciales.

En el desarrollo del proyecto antropológico- arqueológico en Mansión Seré o Atila, que funcionara como centro clandestino de detención, por citar un ejemplo que podemos referir de manera directa, los trabajos arqueológicos han generado (y aún lo siguen haciendo) importante evidencia para el esclarecimiento del genocidio. La visibilidad que adquirió este espacio de memoria, con un fuerte apoyo del estado municipal (Dirección de Derechos Humanos de la Municipalidad de Morón), permitió por un lado que se acercaran ex detenidos a dar su testimonio, otros a consultar sobre su probable detención en el lugar, así como referencias de vecinos acerca del funcionamiento de Mansión Seré como centro de detención. Al mismo tiempo las excavaciones han permitido recuperar los cimientos de la casona y su sótano y en conjunto con las declaraciones de los detenidos, rearmar el plano de la casa y la funcionalidad de los espacios mientras funcionaba como centro de detención (Di Vruno y Seldes 2005, Di Vruno et al 2006).

¿Pero cuántos trabajos arqueológicos hacen referencia a los procesos de genocidio de los pueblos originarios?

En este momento en el cual se están generando interesantes procesos, donde por un lado las organizaciones indígenas reclaman su reconocimiento como actores sociales, reclamando sobre derechos territoriales y reivindicando el respeto por su cultura e identidad, solicitan-do mayor participación y decisión sobre el manejo de los bienes culturales, de su historia y su presente y don-de paralelamente a esto, y probablemente fuertemente vinculado, asistimos al resurgimiento de la "cuestión indígena" como tema de las agendas gubernamentales (Delrio y Lenton 2008), la arqueología se encuentra con- 
minada a comprometerse. Esto genera nuevos desafíos para la disciplina a medida que se avanza en la reflexión sobre el respeto a las comunidades locales, su voz, su relato; abandonando el monólogo arqueológico para transitar instancias de diálogo, de coproducción del conocimiento, y para evaluar cuánto puede hacer hoy la ciencia en pos de la visibilización de la diversidad que engloba aquel "ser argentino", acompañando el proceso que vienen realizando los pueblos originarios.

En este sentido, es importante reconocer que se han generado espacios en los eventos científicos para la discusión acerca de las consecuencias sociales de la arqueología, el trabajo en conjunto con las comunidades; y se han desarrollado simposios y reuniones sobre el trata-miento de los restos óseos humanos y la ética profesional.

Muchos de estos encuentros han generado arduos de-bates y han puesto en evidencia las diferentes posturas alrededor de los derechos de las comunidades a decidir sobre el destino de los restos recuperados por la arqueología (los restos humanos principalmente), poniendo sobre el tapete la discusión acerca de la existencia de una continuidad histórica de los pueblos originarios y su vinculación con las comunidades actuales, un punto que todavía sigue discutiéndose y donde lejos se está de generar un consenso.

Estos debates evidencian que hay temas que no han sido lo suficientemente problematizados por el conjunto de la comunidad arqueológica. El punto de inflexión creemos que sigue siendo el "gran debate" que todavía se debe la arqueología, esto es, la reflexión acerca de cuánto podría contribuir hoy la arqueología para esclarecer procesos genocidas vinculados a los actuales reclamos de los pueblos indígenas.

Concretamente algunos pasos se han dado en este sentido. Algunos arqueólogos han participado en el proceso de restitución y en algunos casos reentierro de restos humanos; se han retirado cuerpos momificados de las vitrinas de algunos museos, algunos han participado como testigos en casos de disputas territoriales de comunidades indígenas por la tenencia de la tierra...un largo camino aún por recorrer....mas sin un verdadero debate y sinceramiento, este tipo de prácticas podrían perdurar en la historia de la disciplina como casos aislados con ese status periférico.

Esperamos con estas reflexiones haber contribuido a la discusión sobre cuál es el lugar que actualmente puede tomar la arqueología en el proceso de conocimiento de nuestra historia, nuestro presente, y los aportes que puede realizar al esclarecimiento de los procesos de etnocidio; más aún, continuar pensando para quiénes se construyen los discursos científicos (Delfino y Rodríguez 1991) y qué es lo que se está legitimando con su práctica.

\section{BIBLIOGRAPHY}

Belli, E., R. Slavuztky y C. Argañaraz (2005). Patrimonio y memoria: el problema de la tierra en Tilcara. En E.Belli y R. Slavutzky (Eds.) Patrimonio en el Noroeste Argentino, (pp. 65 - 126). Buenos Aires: Instituto Interdisciplinario Tilcara, Facultad de Filosofía y Letras. UBA. 
Bechis, M. (1992). Instrumentos metodológicos para el estudio de las relaciones interétnicas en el período formativo y de consolidación de estados nacionales. En C. Hidalgo y L. Tamagno (Comps.) Etnicidad e identidad, (pp.82-108). Buenos Aires: CEAL.

Boasso, F. (2005). Memorias del territorio. Patrimonio en el Noroeste Argentino, pp. 197 - 217. Editado por E. Belli y R. Slavutzky. Instituto Interdisciplinario Tilcara, Facultad de Filosofía y Letras. UBA.

Cruz, P. y Seldes, V. (2005). Patrimonio, identidad y práctica arqueológica en la Quebrada de Humahuaca (Jujuy, Argentina). En E. Belli y R. Slavutzky (Eds.) Patrimonio en el Noroeste Argentino, (pp. 167-195). Bue-nos Aires: Instituto Interdisciplinario Tilcara, Facultad de Filosofía y Letras. UBA

Delfino, D. y Rodríguez, P.G. (1991). Crítica de la arqueología 'pura': de la defensa del patrimonio hacia una arqueología socialmente útil. Inédito.

Delrio, W. y D. Lenton (2008). Negaciones y reconocimientos del genocidio en la política indígena del estado argentino. Trabajo presentado en 3ras Jornadas de Historia de la Patagonia, Bariloche, 6-8 de noviembre de 2008.

Delrio, W., Lenton, D., Musante, M., Nagy, M., Papazian, A. y Pérez, P. (2010). Prácticas genocidas y Pueblos Originarios en Argentina. Trabajo presentado en III Seminario Internacional Políticas de la Memoria "Recordando a Walter Benjamin: Justicia, Historia y Verdad. Escrituras de la Memoria". Buenos Aires, 28, 29 y 30 de octubre de 2010. Centro Cultural de la Memoria Haroldo Conti.

Di Vruno, A. y Seldes, V. (2005). Proyecto Antropológico - Arqueológico "Mansión Seré". El Provenir de la Memoria: 137 - 152. Segundo Coloquio Interdisciplinario de Abuelas de Plaza de Mayo "El Porvenir de la Memoria", 8 y 9 de abril de 2005. Escuela Superior de Comercio Carlos Pellegrini. UBA.

Di Vruno, A., Seldes, V., Noel, D.A., De Haro, M.T., Do-val, J, Giorno, P., Vázquez, L. (2006).

Arqueología en un Centro Clandestino de Detención . El caso Mansión Seré - Atila”. III Congreso Nacional de Arqueología Histórica. Rosario 18 al 20 de mayo de 2006.

Endere, M. L y Curtoni, R. (2006). Entre Lonkos y “ólogos”. La participación de la comunidad indígena Rankulche de Argentina en la investigación arqueológica. Arqueología Suramericana, 2 (1): $72-92$.

Machaca, R. (2007). La escuela Argentina en la celebración del encuentro con el "nosotros indígena". La Paz: Plural, PROEIB Andes, UMSS, Ministerio de Educación ciencia y tecnología. Presidencia de la Argentina.

Trinchero, H. (2000). Los dominios del demonio. Civilización y barbarie en las fronteras de la nación. Buenos Aires: EUDEBA.

Zaburlin, M.A. (2009). Historia de la ocupación del Pucará de Tilcara (Jujuy, Argentina). Intersecciones en Antropología, 10 (1): 89 - 103.

\section{NOTES}

1. Somos conscientes de la superposición de los conceptos genocidio cultural y etnocidio. Sin embargo, elegimos esta expresión dado que estamos convencidos de que el etnocidio, en todo caso, es una manifestación del genocidio. Nuestra expresión "genocidio cultural" intenta enfatizar la vía cultural por la cual también se realiza el genocidio. 


\section{AUTHOR}

\section{VERÓNICA SELDES}

Consejo Nacional de Investigaciones Científicas y Técnicas (CONICET)- Instituto Nacional de Pensamiento Latinoamericano (INAPL), Argentina.

Correo electrónico: vseldes@gmail.com 